Supporting Information for

\title{
Metal-Free Polymer-Based Affinity Medium for Selective Purification of His6-Tagged Proteins
}

\author{
Keiichi Yoshimatsu, ${ }^{\dagger+}$ Krista R. Fruehauf, ${ }^{\dagger}$ Quanhong Zhu, ${ }^{\dagger}$ Adam Weisman, ${ }^{\dagger}$ Jun Fan, ${ }^{\dagger}$ \\ Min Xue, ${ }^{\dagger}$ John M. Beierle, ${ }^{\dagger}$ Paul E. Rose, ${ }^{\S}$ Jennifer Aral,${ }^{\S}$ Linda F. Epstein, ${ }^{\S}$ Philip Tagari, ${ }^{\S}$ \\ Les P. Miranda, ${ }^{\S}$ and Kenneth J. Shea*,† \\ ${ }^{\dagger}$ Department of Chemistry, University of California, Irvine, Irvine, California 92697, United States \\ ${ }^{\S}$ Department of Chemistry, Missouri State University, 901 South National Avenue, Springfield, \\ Missouri, 65897, United States \\ ${ }^{\#}$ Therapeutic Discovery, Amgen Inc., One Amgen Center Drive, Thousand Oaks, California 91320, \\ United States \\ *e-mail: kjshea@uci.edu
}

\section{Table of Contents}

Supporting Methods

Scheme S1. Steps in the preparation of polymer-coated Sepharose CL-4B beads

\section{Supporting Data}

Table S1. Yield and hydrodynamic diameter of NPs.

Table S2. Result of elemental analysis. The values are weight \% per total mass of dried samples.

Figure S1. Binding curve of AcPhe40 for Met-His6-PreScission peptide

Figure S2. ${ }^{1} \mathrm{H}$ NMR spectrum of $N$-acryloyl $L$-phenylalanine $\left(\mathrm{CD}_{3} \mathrm{OD}, 500 \mathrm{MHz}\right)$

Figure S3. ${ }^{13} \mathrm{C}$ NMR spectrum of $N$-acryloyl $L$-phenylalanine (CD33OD, $125 \mathrm{MHz}$ )

Figure S4. ${ }^{1} \mathrm{H}$ NMR spectrum of $N$-acryloyl $L$-leucine $\left(\mathrm{CDCl}_{3}, 500 \mathrm{MHz}\right)$

Figure S5. ${ }^{13} \mathrm{C}$ NMR spectrum of $N$-acryloyl $L$-leucine $\left(\mathrm{CDCl}_{3}, 125 \mathrm{MHz}\right)$

Figure S6. ${ }^{1} \mathrm{H}$ NMR spectrum of $N$-acryloyl $L$-alanine (DMSO- $d_{6}, 500 \mathrm{MHz}$ )

Figure $S 7 .{ }^{13} \mathrm{C}$ NMR spectrum of $N$-acryloyl $L$-alanine (DMSO- $d 6,125 \mathrm{MHz}$ )

Figure S8. ${ }^{1} \mathrm{H}$ NMR spectrum of $N$-propargyl acrylamide $\left(\mathrm{CDCl}_{3}, 500 \mathrm{MHz}\right)$

Figure S9. ${ }^{13} \mathrm{C} \mathrm{NMR}$ spectrum of $\mathrm{N}$-propargyl acrylamide $\left(\mathrm{CDCl}_{3}, 125 \mathrm{MHz}\right)$ 


\section{Supporting Methods}

\section{NMR Measurements}

All ${ }^{1} \mathrm{H}$ NMR and ${ }^{13} \mathrm{C}$ NMR spectra were recorded at $500 \mathrm{MHz}$ and $125 \mathrm{MHz}$, respectively, on a

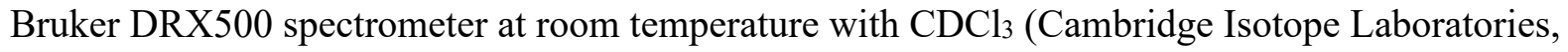
Inc), $\mathrm{CD}_{3} \mathrm{OD}$ (Acros Organic), or DMSO- $d_{6}$ (Acros Organic) as the solvent. The chemical shifts $(\delta)$ were referenced to as an internal standard, tetramethylsilane (TMS).

\section{$\underline{\text { Elemental analyses }}$}

Elemental analyses of the unmodified and polymer-coated agarose beads were performed by Atlantic Microlab (Norcross, GA).

i)

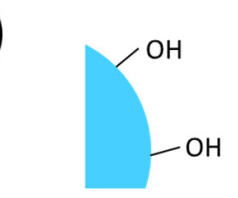

Sepharose CL-4B

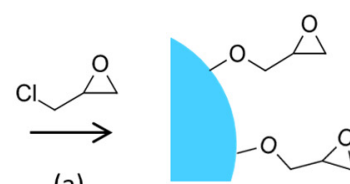

(a)

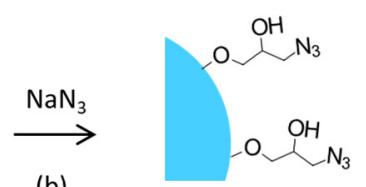

(b)
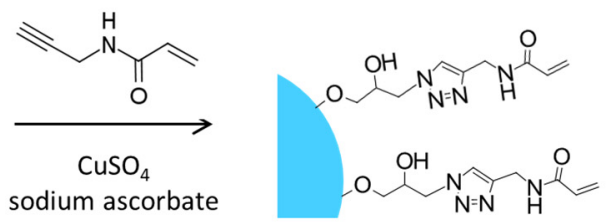

(c)

ii)
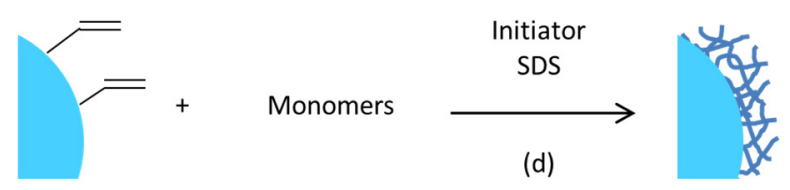

Scheme S1. Steps in the preparation of polymer-coated Sepharose CL-4B beads 


\section{Supporting Data}

Table S1. Yield and hydrodynamic diameter of NPs.

\begin{tabular}{cccc} 
Sample & \multicolumn{2}{c}{ Hydrodynamic diameter } & Yield $^{b}$ \\
AAc5/PAm20 & nm & PDI & $\%$ \\
AAc5/PAm40 & 127 & 0.071 & 85 \\
AAc20/PAm20 & 108 & 0.087 & 57 \\
AAc20/PAm40 & 100 & 0.063 & 80 \\
AAc5/TBAm40 & 74 & 0.064 & 58 \\
AAc20/TBAm40 & 85 & 0.060 & 85 \\
PAm20 & 97 & 0.055 & 80 \\
PAm40 & 109 & 0.42 & 78 \\
TBAm40 & 85 & 0.42 & 65 \\
NIPAm & 75 & 0.087 & 88 \\
AcPhe20 & 431 & 0.166 & 75 \\
AcPhe40 & 106 & 0.120 & 77 \\
AcLeu20 & 94 & 0.106 & 67 \\
AcLeu40 & 81 & 0.068 & 88 \\
AcAla20 & 76 & 0.077 & 75 \\
AcAla40 & 817 & 0.113 & 69 \\
\hline
\end{tabular}

${ }^{a}$ Intensity-based calculated mean value (Z-average) in $\mathrm{H}_{2} \mathrm{O}$ at $25^{\circ} \mathrm{C}$ by dynamic light scattering (DLS) instrument equipped with Zetasizer software Ver. 6.12 (Zetasizer Nano ZS, Malvern Instruments Ltd) ${ }^{b}$ Determined by a gravimetric analysis of lyophilized polymer NPs.

Table S2. Result of elemental analysis. The values are weight \% per total mass of dried samples.

$\begin{array}{cccc}\text { Sample } & \text { C } & \text { H } & \text { N } \\ \text { Sepharose }{ }^{\circledR} \text { CL-4B beads, before modification } & 46.5 & 6.4 & 0 \\ \text { Polymer-coated beads } & 48.1 & 6.67 & 3.57\end{array}$




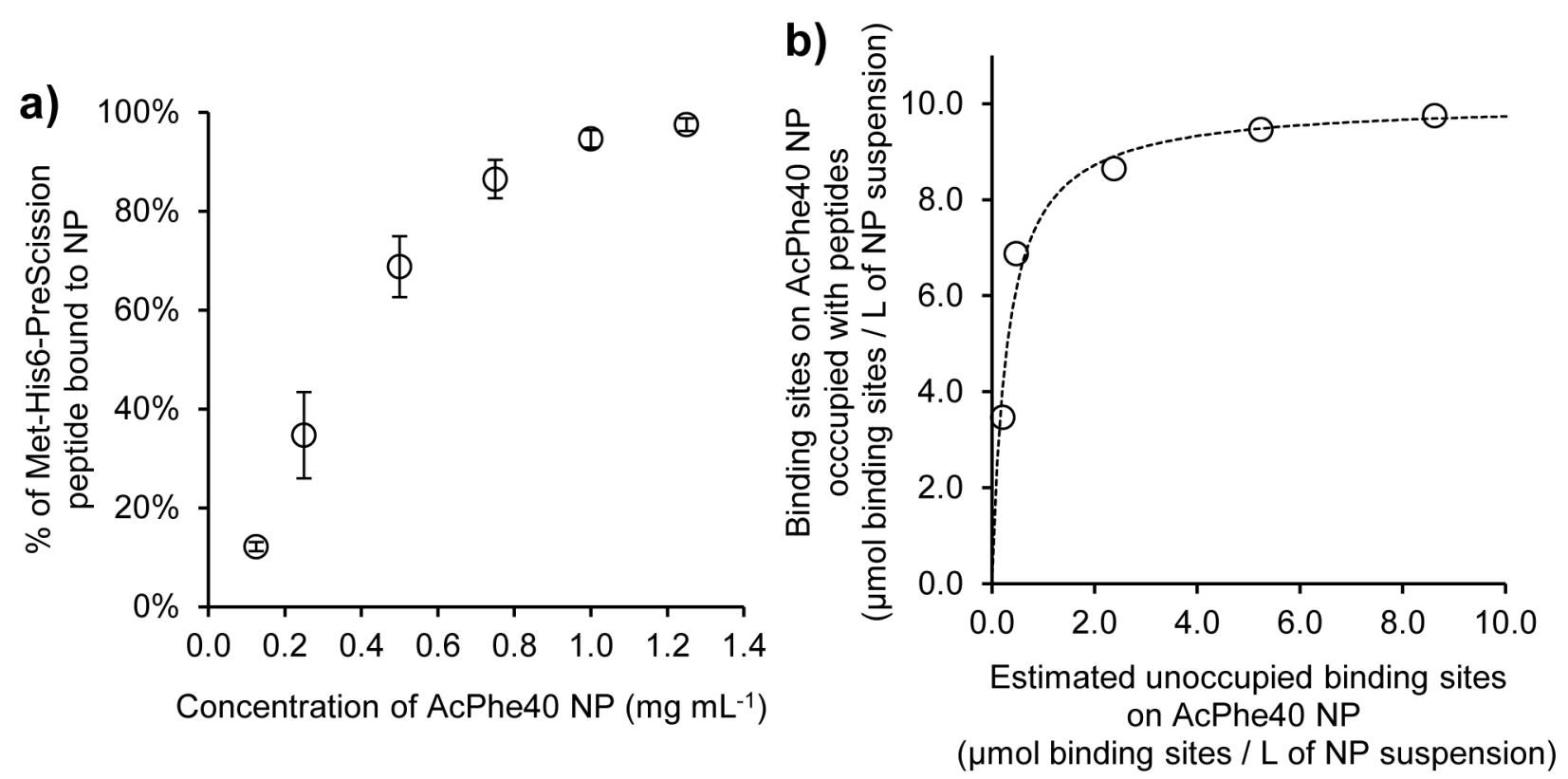

Figure S1. a) Equilibrium binding curve of AcPhe40 NP for Met-His6-PreScission peptide in 15 $\mathrm{mM}$ Tris- $\mathrm{HCl}$ buffer ( $\mathrm{pH} 7.8)$ containing $0.1 \%$ Tween $20(\mathrm{w} / \mathrm{v})$. Concentration of peptide $=10 \mu \mathrm{M}$ $(18.55 \mu \mathrm{g} / \mathrm{mL})$. b) Binding isotherm of AcPhe40 NP for Met-His6-PreScission peptide. The plot was established based on the assumption of $14.7 \mathrm{nmol}$ of peptide binding sites being present in every $\mathrm{mg}$ of AcPhe40 NP. The dashed line is the best fitted curve obtained by using the one-site model with the parameters of $B_{\max }=10.03 \mu \mathrm{mol}$ binding sites / L of NP suspension and $K_{\mathrm{d}}=300.2 \mathrm{nM}$. 
1H spectrum

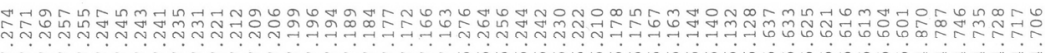

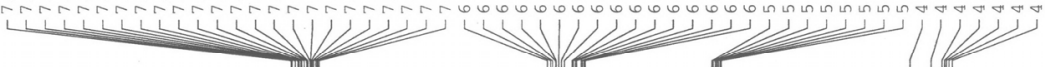

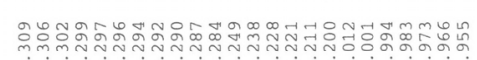

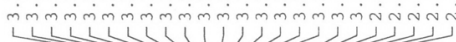

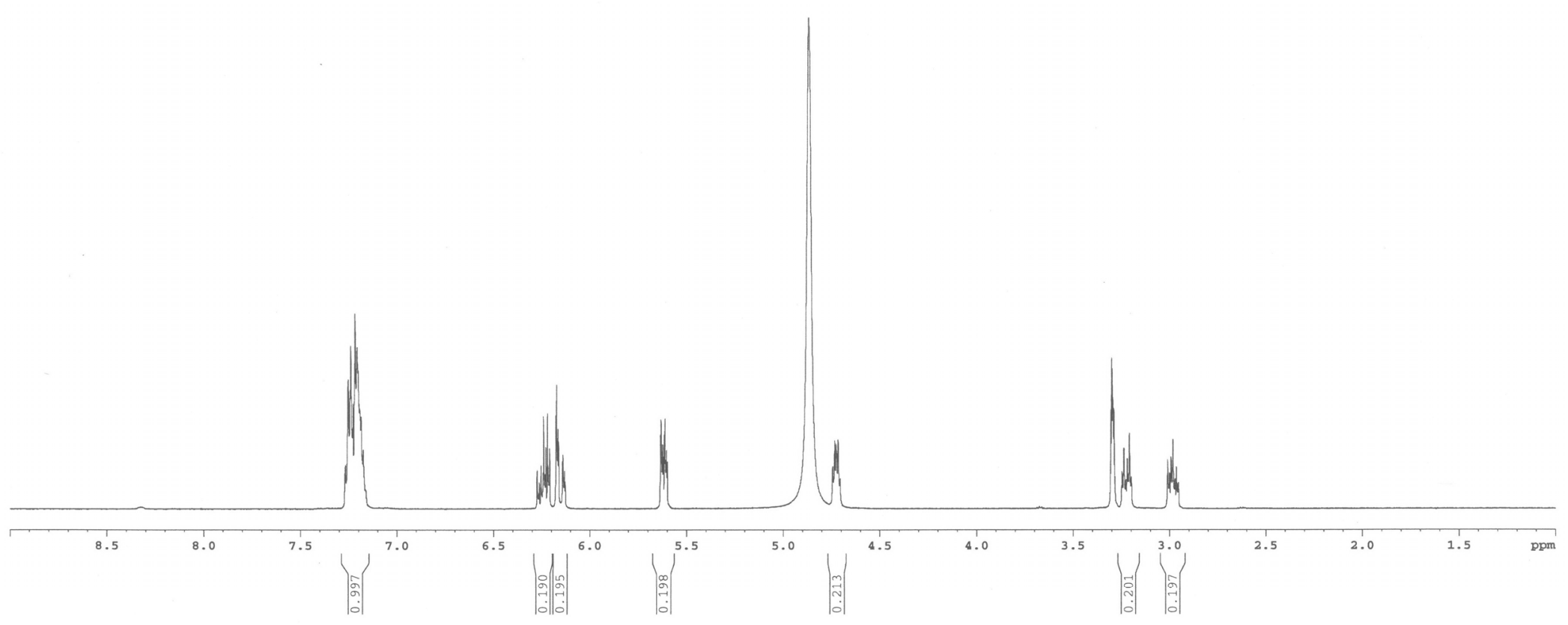

Figure S2. ${ }^{1} \mathrm{H}$ NMR spectrum of $N$-acryloyl $L$-phenylalanine $\left(\mathrm{CD}_{3} \mathrm{OD}, 500 \mathrm{MHz}\right)$ 
$13 \mathrm{C}$ spectrum with $1 \mathrm{H}$ decoupling
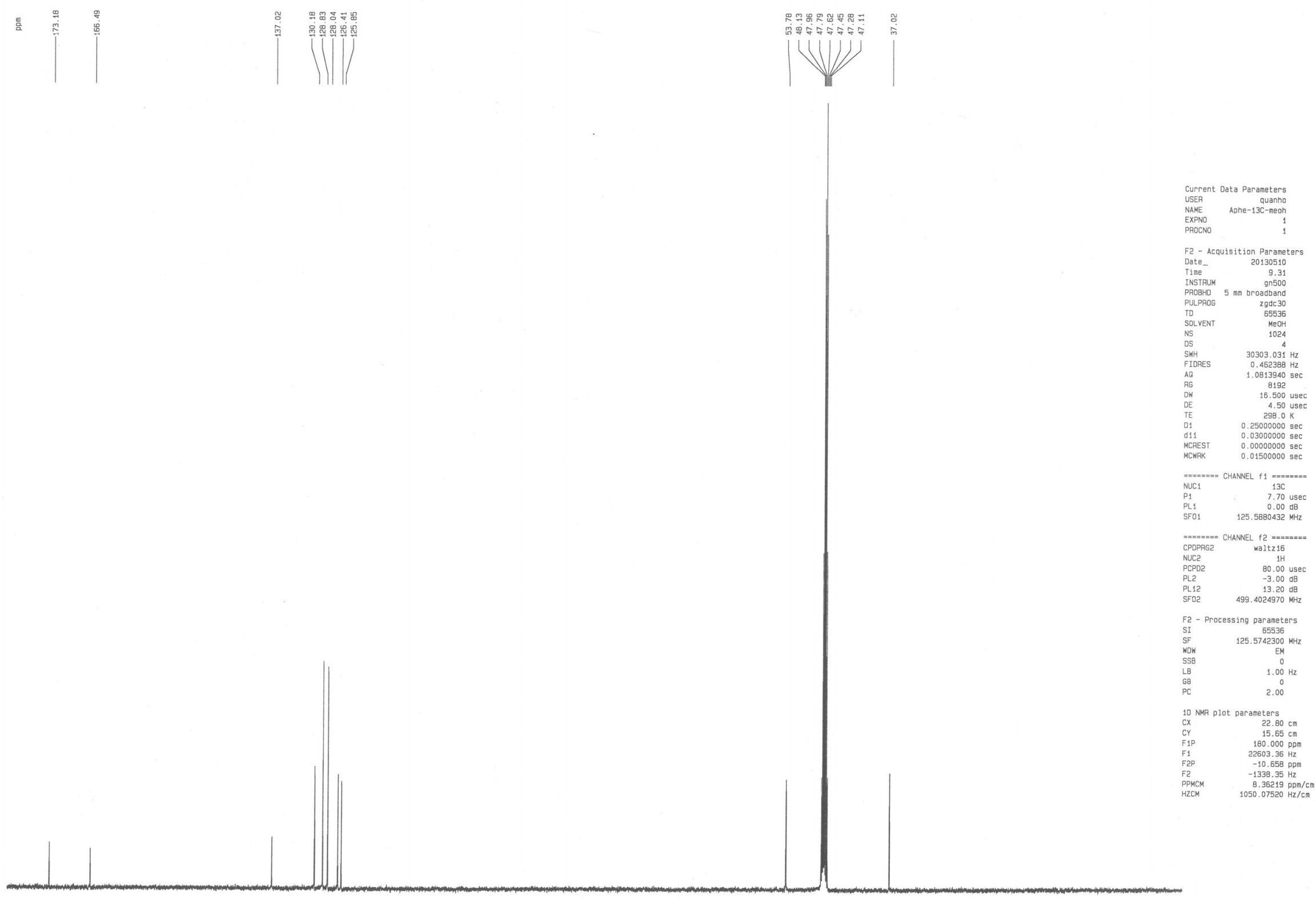

Figure S3. ${ }^{13} \mathrm{C}$ NMR of $N$-acryloyl $L$-phenylalanine (CD3OD, $125 \mathrm{MHz}$ ) 


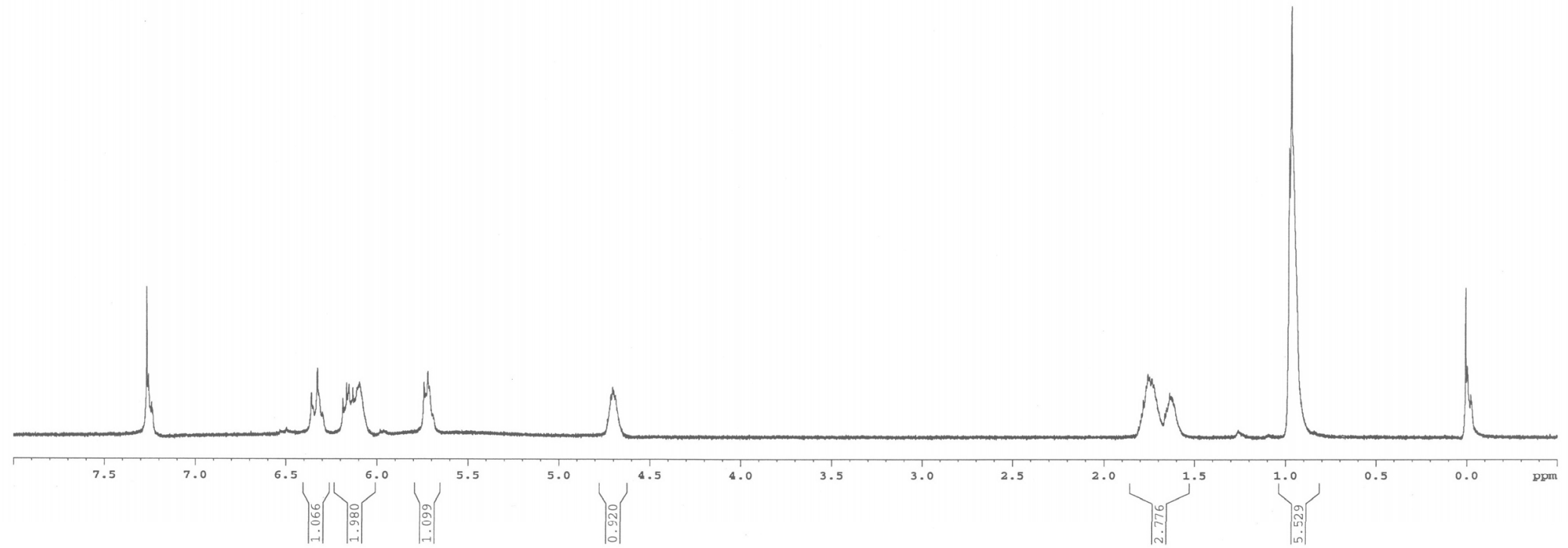

Figure S4. ${ }^{1} \mathrm{H}$ NMR spectrum of $N$-acryloyl $L$-leucine $\left(\mathrm{CDCl}_{3}, 500 \mathrm{MHz}\right)$ 
$13 \mathrm{C}$ spectrum with $1 \mathrm{H}$ decoupling

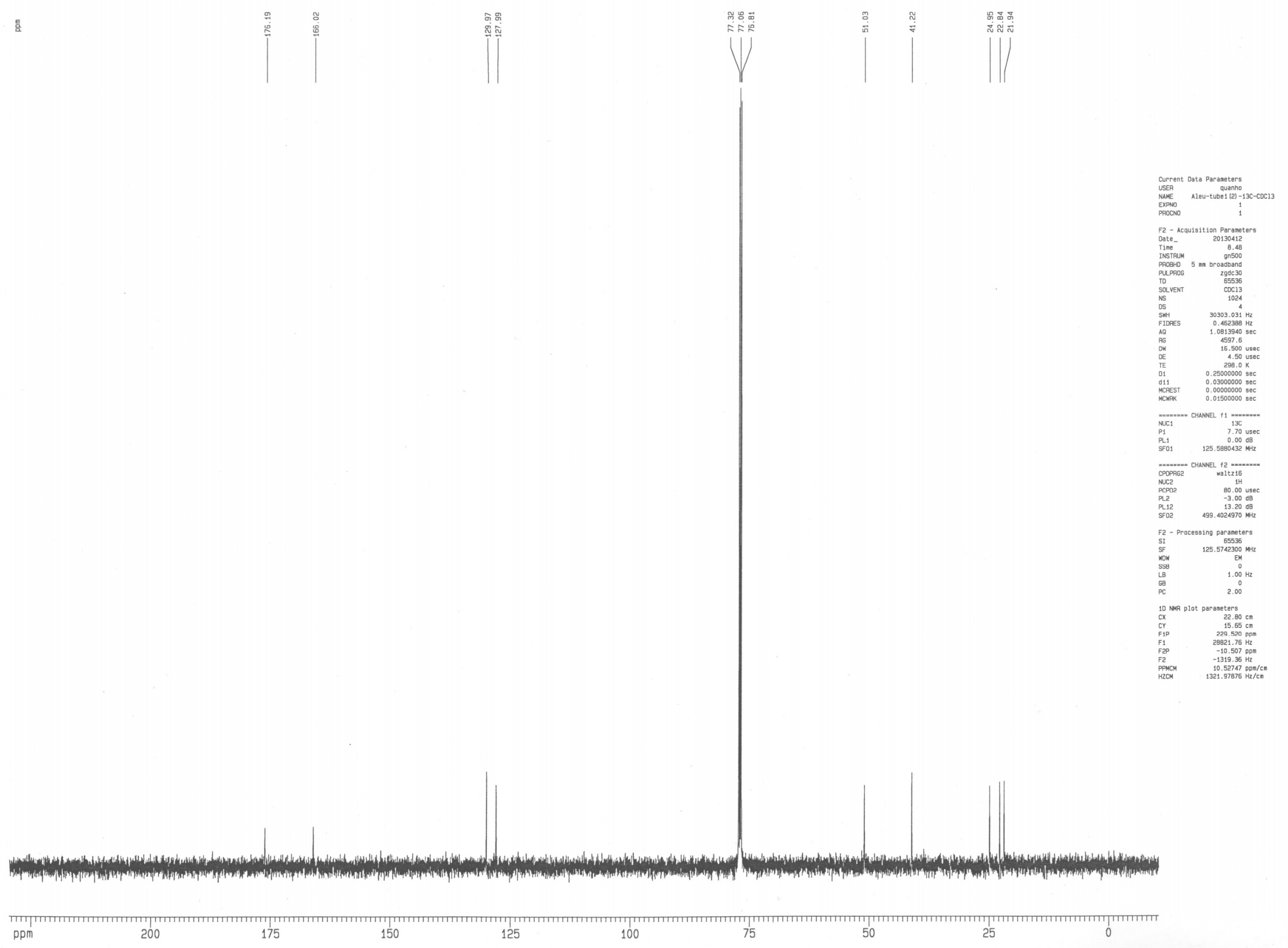

Figure S5. ${ }^{13} \mathrm{C}$ NMR spectrum of $N$-acryloyl $L$-leucine $\left(\mathrm{CDCl}_{3}, 125 \mathrm{MHz}\right)$ 


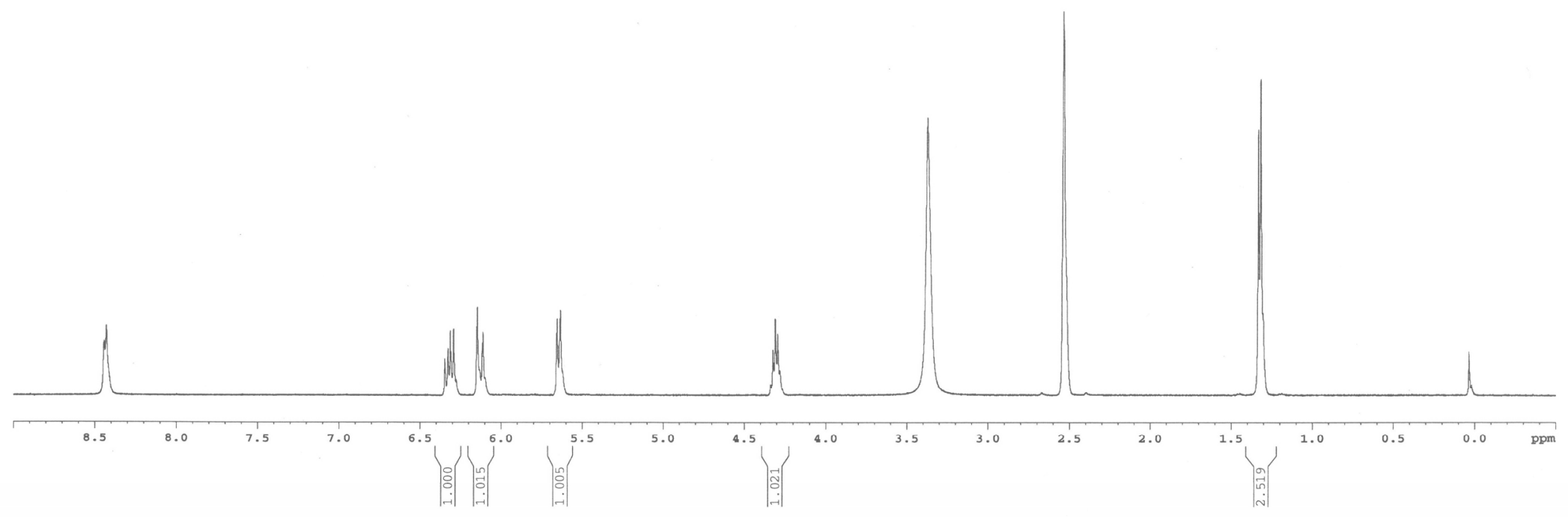

Figure S6. ${ }^{1} \mathrm{H}$ NMR spectrum of $N$-acryloyl $L$-alanine (DMSO-d6, $500 \mathrm{MHz}$ ) 
Z-restored spin-echo $13 \mathrm{C}$ spectrum with $1 \mathrm{H}$ decoupling
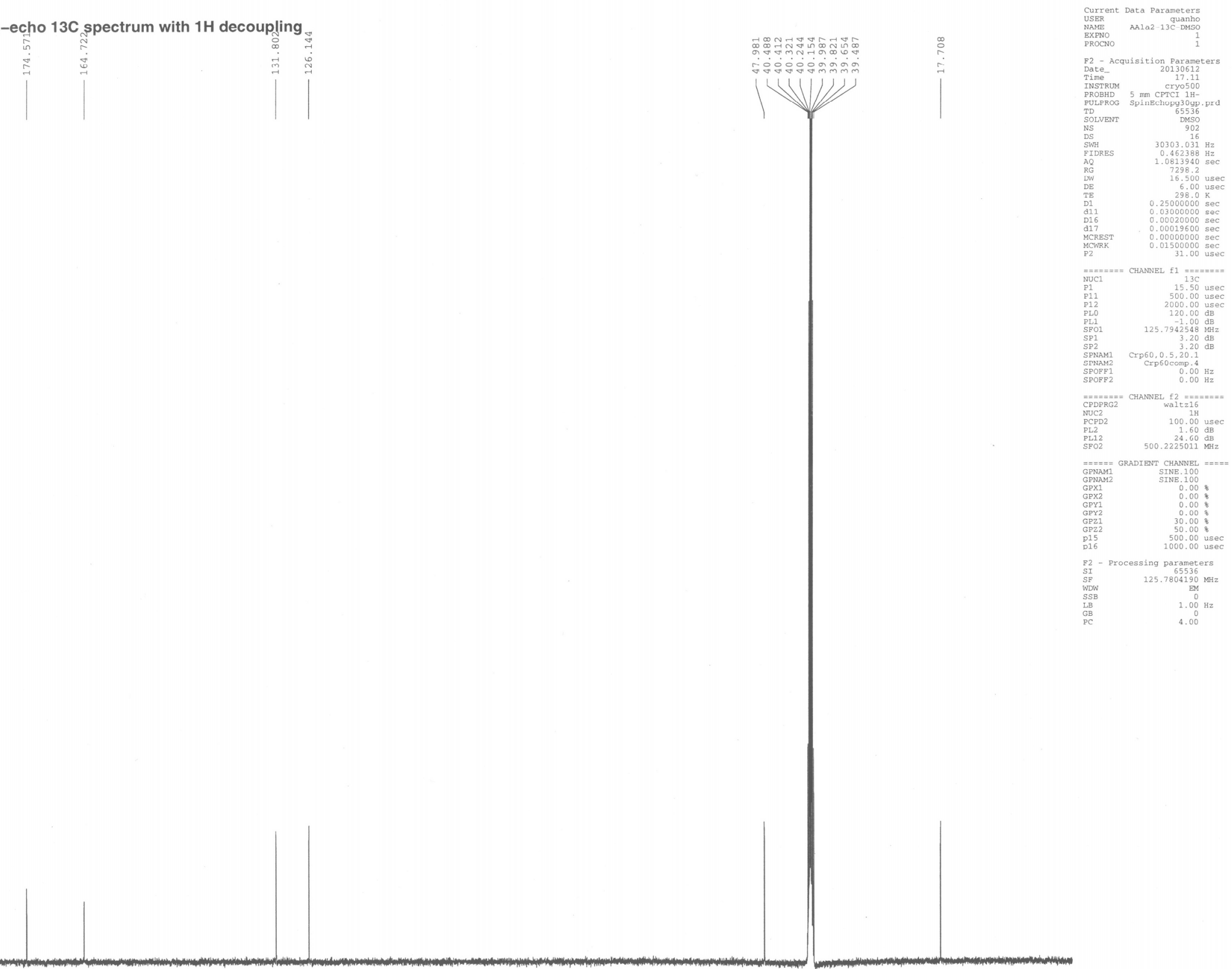

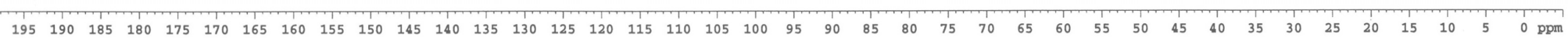

Figure S7. ${ }^{13} \mathrm{C}$ NMR spectrum of $N$-acryloyl $L$-alanine (DMSO- $d 6,125 \mathrm{MHz}$ ) 


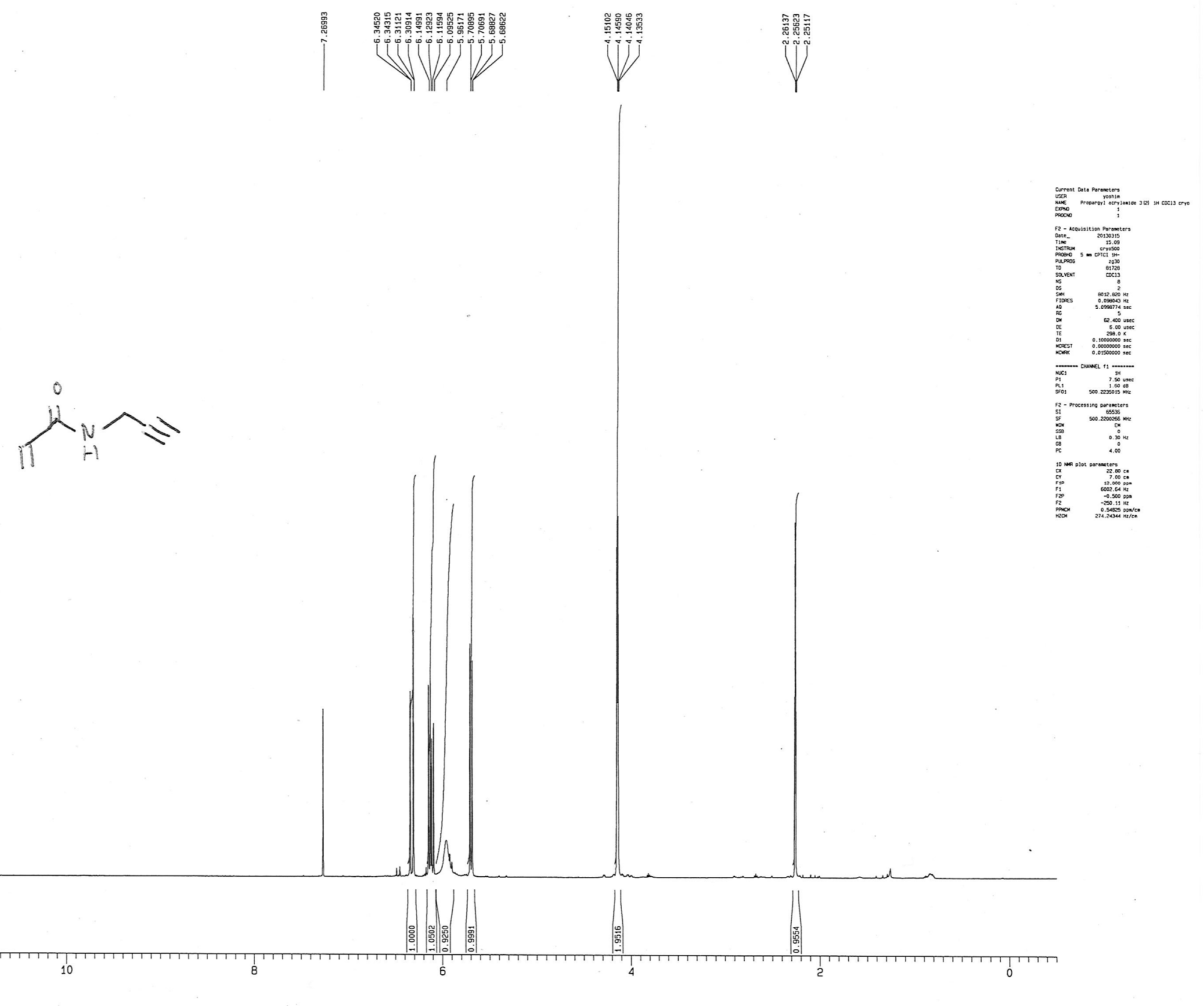

Figure S8. ${ }^{1} \mathrm{H}$ NMR spectrum of $N$-propargyl acrylamide $\left(\mathrm{CDCl}_{3}, 500 \mathrm{MHz}\right)$ 


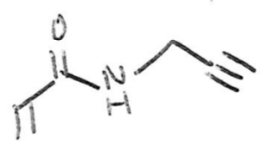

Figure S9. ${ }^{13} \mathrm{C}$ NMR spectrum of $N$-propargyl acrylamide $\left(\mathrm{CDCl}_{3}, 125 \mathrm{MHz}\right)$ 